\title{
INTERCULTURALIDADE NA FORMAÇÃO DE PROFESSORES/AS INDÍGENAS: REFLEXÕES A PARTIR DE UM OLHAR SOBRE O PENSAMENTO AMERÍNDIO
}

\author{
Beatriz Osorio Stumpf ${ }^{i}$
}

\begin{abstract}
Resumo: Este trabalho desenvolve reflexões sobre interculturalidade na formação continuada de professores indígenas, partindo de uma experiência desenvolvida na Amazônia brasileira, em diálogo com autores que contribuem para uma maior compreensão do pensamento ameríndio. $\mathrm{O}$ acompanhamento participativo e investigativo desse processo de formação revelou a riqueza e a profundidade do conhecimento indígena, com seus grandes potenciais de contribuição para a educação em geral e para a sociedade como um todo, ressaltando a importância do apoio ao registro desses saberes, em diferentes formas e linguagens, tendo a arte uma função essencial.
\end{abstract}

Palavras-chave: Interculturalidade; Formação; Professores Indígenas; Bem Viver.

\section{INTERCULTURALIDAD EN LA FORMACIÓN DE PROFESORES/AS INDÍGENAS: REFLEXIONES A PARTIR DE UNA MIRADA SOBRE EL PENSAMIENTO AMERINDIO}

Resumen: Este trabajo desarrolla reflexiones sobre interculturalidad en la formación continuada de profesores indígenas, partiendo de una experiencia desarrollada en la Amazonia brasileña, en diálogo con autores que contribuyen a la mayor comprensión del pensamiento amerindio. El acompañamiento participativo e investigativo de ese proceso de formación reveló la riqueza y la profundidad del conocimiento indígena, con sus grandes potenciales de contribución a la educación en general y a la sociedad en su conjunto, resaltando la importancia del apoyo al registro de esos saberes, en diferentes formas y lenguajes, teniendo el arte una función esencial.

Palabras clave: Interculturalidad; Formación; Profesores Indígenas; Bien vivir.

\section{Introdução}

Este trabalho desenvolve reflexões sobre interculturalidade na formação continuada de professores/as indígenas, a partir de experiência desenvolvida no alto rio Negro, no município de São Gabriel da Cachoeira, Estado do Amazonas, com oito etnias indígenas, através da ação 
"Saberes Indígenas na Escola", uma política pública educacional do governo brasileiroii. O acompanhamento participativo e investigativo dessa formação proporcionou intensa observação e reflexão sobre o encontro entre diferentes culturas e visões de mundo na construção coletiva de métodos e instrumentos pedagógicos para a Educação Escolar Indígena.

A discussão tem como base principal o estabelecimento de relações dialógicas entre algumas vozes de educadores/as participantes do curso e textos de autores que contribuem para uma compreensão mais profunda do pensamento ameríndio, como Rodolfo Kusch e Fernando Huanacuni Mamani.

O texto se divide em três etapas: contextualizações, reflexões e considerações. A parte inicial oferece elementos importantes para as observações posteriores, caracterizando a região e seus povos, a situação local da educação escolar indígena, e o processo de formação continuada de professores/as indígenas que originou a discussão. A segunda seção tece reflexões sobre pensamento ameríndio, interculturalidade, interdisciplinaridade, bem viver e descolonização, além de contribuições no âmbito da formação de educadores/as indígenas, desenvolvendo diálogos a partir de observações e depoimentos de professores/as ameríndios, no entrelaçamento com pensamentos de outros/as autores/as. O último momento reúne as principais considerações alcançadas a partir das observações e diálogos, bem como do processo reflexivo e de escrita.

\section{Contextualizações}

A região do alto rio Negro:

O cenário da presente pesquisa, com sua resultante reflexão, constitui o município de São Gabriel da Cachoeira, Estado do Amazonas, alto rio Negro, extremo noroeste da Amazônia brasileira, na fronteira com a Colômbia e a Venezuela.

Conforme FOIRN/ISA (1998), a região do alto e médio rio Negro é tradicionalmente habitada há pelo menos 2.000 anos por um diversificado sistema de povos indígenas, com imensa riqueza cultural e linguística. Na atualidade, vivem na região vinte e duas etnias, as quais utilizam idiomas que pertencem a quatro diferentes famílias linguísticas: Aruak, Maku, Tukano e Yanomami. São faladas mais de vinte línguas, sendo que algumas são usadas por 
milhares de pessoas, como o tukano e o baniwa. É comum que pessoas da região falem várias línguas indígenas, além do português e do espanhol. Algumas etnias, ou partes delas, deixaram de falar suas línguas de origem, adotando outros idiomas, como é o caso dos Tariano no Uaupés, que atualmente falam tukano; ou dos Tukano que foram para o médio rio Negro e adotaram o nheengatu, a língua geral amazônica.

A cidade de São Gabriel da Cachoeira teve um aumento significativo de sua população nos últimos 20 anos, devido a um conjunto de fatores, como o estabelecimento de contingentes militares, o crescimento do comércio e outros serviços, e o fluxo migratório das comunidades indígenas. O total da população regional é de cerca de 35.000 habitantes, sendo que a maior parte vive em povoados e sítios espalhados pelos rios da região. São aproximadamente 732 povoados, abrangendo desde pequenos sítios habitados por apenas um casal até grandes povoações com mais de mil pessoas. Muitos aldeamentos são ocupados por várias etnias, que algumas vezes utilizam não somente dialetos distintos, como também línguas pertencentes a diferentes famílias linguísticas.

Cada uma das vinte e duas etnias se diferencia das outras, pelo menos em alguns aspectos. No entanto, nesse panorama de diversidade cultural encontram-se muitas características comuns, principalmente em relação aos mitos, atividades de subsistência, cultura material e arquitetura tradicional. Esses povos indígenas desenvolveram, ao longo de milhares de anos, estratégias refinadas de adaptação ao ambiente local, o qual é conhecido como o mais pobre de toda a Amazônia, pela baixa fertilidade e acidez de suas terras e escassez de peixes nos rios. A zona é drenada pelo curso alto e médio do rio Negro, que recebe as águas de um grande número de rios e igarapés, como o Uaupés, Içana, Curicuriari, Marauiá e Xié, constituindo a maior bacia de águas negras do mundo. Conforme Ricardo \& Antongiovanni (2008), a área do alto rio Negro possui formações florestais de terra firme, florestas inundadas (igapós) e a catinga do rio Negro (campinarana), que cobre a maior parte das Terras Indígenas, cujos solos são intensamente ácidos, arenosos e lixiviados.

Segundo Cabalzar e Ricardo (1998), a região do alto e médio rio Negro apresenta várias características ecológicas que a diferenciam dentro do contexto da Bacia Amazônica. As águas do rio Negro são caracterizadas por extrema acidez e desprovimento de nutrientes, ocasionando a predominância de solos pobres e da baixa disponibilidade de peixes e de caça. Pesquisas realizadas na região têm indicado que estas peculiaridades exerceram importante 
influência na história e nas formas de organização social das populações indígenas, levando ao desenvolvimento de conhecimentos, práticas, técnicas e instrumentos aprimorados para o manejo dos recursos naturais. Atualmente, torna-se interessante a valorização destes saberes e de suas potencialidades para o uso de alternativas econômicas sustentáveis, que contribuam para a melhoria das condições de vida das comunidades ameríndias.

A população indígena dessa região é bastante organizada, principalmente através da Federação das Organizações Indígenas do Rio Negro (FOIRN), criada em 1987, como resultado do movimento pela demarcação de uma terra indígena contínua, e tendo por objetivo a defesa dos direitos coletivos dos povos indígenas.

\section{A Educação Escolar Indígena no alto rio Negro:}

De acordo com Cabalzar \& Oliveira (2012), as instituições religiosas exerceram grande influência na educação escolar do alto rio Negro, com uma perspectiva pedagógica colonizadora, criticando e/ou proibindo línguas, ritos e crenças indígenas. A presença das missões educacionais salesianas começou em 1914, se estabelecendo inicialmente em São Gabriel da Cachoeira e posteriormente nos povoados de Taracuá, Iauaretê, Pari-Cachoeira, Assunção e Maturacá. A partir de 1948, o protestantismo se inseriu na região, especialmente no rio Içana.

Com as evidências de desgastes e perdas de importantes conhecimentos tradicionais regionais, lideranças indígenas passaram a desenvolver uma visão crítica sobre esses sistemas de ensino. A partir dos anos 1980, o movimento indígena local, através da FOIRN, passou a realizar discussões e ações na área da educação escolar indígena, delineando sistemas educacionais próprios, de modo a romper com os modelos externos introduzidos. Algumas iniciativas foram consolidadas com este processo, com exemplos inovadores, como as escolas diferenciadas das etnias Tuyuka, Baniwa e Tukano, as quais possuem currículos e métodos adaptados à cultura e ao ritmo de vida das comunidades. A construção já avançou para a elaboração de um plano de ensino superior diferenciado, com o Programa de Formação Avançada, elaborado coletivamente (BARRETTO FILHO, 2012).

No entanto, Santos e Faria (2016) observam um retrocesso das conquistas educacionais do movimento indígena no município de São Gabriel da Cachoeira, o qual já foi 
reconhecido no cenário nacional como exemplo de educação escolar indígena diferenciada. Atualmente as escolas são mais direcionadas para a alfabetização apenas na língua portuguesa e a formação de professores/as segue de forma padronizada no modelo ocidental. As autoras informam que o município de São Gabriel da Cachoeira conta com 230 escolas espalhadas nas mais de 700 comunidades rurais indígenas, e quatro escolas na sede do município. Porém, esses estabelecimentos apresentam diferentes situações de reconhecimento e oficialização. Diversas escolas ainda não obtiveram a aprovação de seus Projetos Políticos Pedagógicos Indígenas (PPPI), sendo que muitas propostas terminam sendo alteradas para que sejam aprovados.

Menezes (2012), analisando iniciativas educacionais locais, aborda declínios que podem ocorrer nas escolas diferenciadas, se não houver acompanhamento de um processo contínuo de formação e discussão, com construção de métodos, currículos, programas e sistemas de avaliação diferenciados, junto à produção de materiais e definição de calendários escolares contextualizados à realidade sociocultural de cada comunidade indígena.

\section{A formação continuada de professores/as indígenas:}

A presente reflexão transcorre a partir do acompanhamento participativo e investigativo de um processo de formação continuada de professores/as indígenas desenvolvido no Instituto Federal de Educação, Ciência e Tecnologia da Amazonas - IFAM Campus São Gabriel da Cachoeira/ AM, através da ação "Saberes Indígenas na Escola", política pública integrada ao Programa Nacional dos Territórios Etnoeducacionais Indígenas ${ }^{\mathrm{iii}}$, no Eixo Pedagogias diferenciadas e uso de línguas indígenas.

Através da formação continuada para professores indígenas, mais especificamente os que atuam nos anos iniciais, a ação visa proporcionar apoio pedagógico, contribuindo para o aperfeiçoamento docente, principalmente em métodos de alfabetização, letramento e etnomatemática. A formação é direcionada para pesquisas que resultem na produção de materiais didáticos e paradidáticos, atendendo às especificidades que fundamentam os projetos educativos nas comunidades indígenas. O programa também oferece subsídios à elaboração de currículos, definição de metodologias e sistemas de avaliação que atendam às peculiaridades dos processos pedagógicos e dos conhecimentos dos povos indígenas. Esse 
processo formativo torna possível a ampliação do atendimento na perspectiva de aperfeiçoamento pedagógico de professores indígenas, contribuindo para a melhoria de suas atuações educacionais nas escolas indígenas, instrumentalizando-os e propiciando espaços de construção para uma prática pedagógica diferenciada.

A Ação Saberes Indígenas na Escola está fundamentada nos princípios de especificidade, organização comunitária, multilinguismo e interculturalidade. A formação desenvolvida pelo IFAM - Polo São Gabriel da Cachoeira, por meio dessa política pública, ocorreu de forma integrada às ações do movimento educacional indígena existente na região, em seu processo de construção de uma educação escolar diferenciada. Portanto, de acordo com as especificidades regionais, foram acrescentados outros princípios: concepção sistêmica de educação, interdisciplinaridade, ação reflexiva em conexão com a realidade, manejo do mundo, ensino pela pesquisa e autonomia.

Esse processo formativo contemplou 60 professores indígenas, no período 2015-2016, no curso denominado Aperfeiçoamento em Educação Escolar Indígena. Em virtude das grandes distâncias das comunidades, a formação ocorreu de forma intensiva, distribuída em duas etapas, e contemplando atividades de pesquisa entre elas. A primeira etapa contou com 120 horas de trabalho, desenvolvidas ao longo de quinze dias, com abordagem introdutória de todos os temas, incluindo concepções metodológicas, como o ensino pela pesquisa, com orientações e planejamentos para o trabalho de campo. No período entre as etapas, os/as professores/as desenvolveram atividades investigativas nas comunidades onde lecionam, de acordo com temas previamente escolhidos, registrando os dados obtidos. Na segunda etapa, com um total de 80 horas, ao longo de dez dias, foram trabalhados os registros trazidos pelos/as participantes, através de dinâmicas construtivas, para a elaboração coletiva de métodos de ensino e de materiais didáticos.

Participaram desta formação professores indígenas das etnias: Yanomami, Baré, Tukano, Tariano, Dessano, Piratapuia, Kuripaco e Baniwa. Considerando esta grande diversidade de etnias, com suas especificidades, foram organizados grupos de trabalho, de modo a permitir a construção coletiva de materiais didáticos específicos para cada etnia, contemplando suas línguas e características, respeitando e valorizando a potencialidade etnolinguística da região. 
Foram oferecidos elementos para a construção de concepções de ensino, métodos e materiais pedagógicos para a educação escolar indígena diferenciada das etnias participantes. Estes elementos correspondem às áreas da alfabetização, letramento e ciências da natureza. Foi abordada uma concepção de integração entre estas temáticas, de forma interdisciplinar, principalmente a partir das disciplinas "Elementos para a construção da Escola Indígena Diferenciada" e "Educação Multicicladaiv".

Para a apresentação dos subsídios e a criação de contextos de elaboração de estratégias pedagógicas e de materiais, foram utilizados métodos diversos, como aula expositiva dialogada com uso de recursos audiovisuais, dinâmicas de grupo, apresentação de estudos de caso das escolas diferenciadas já consolidadas, trocas de experiências, jogos de aprendizagem, entre outros. A metodologia de trabalho se constituiu também, de forma processual e coletiva, através do compartilhamento de conhecimentos pelos pesquisadores indígenas, orientadores de estudo, coordenações e professores alfabetizadores cursistas, considerando suas realidades pedagógicas, sociolinguísticas e antropológicas.

\section{Reflexões}

A formação de professores/as indígenas enfrenta o desafio do trabalho colaborativo entre diferentes culturas, com suas distintas visões de mundo, sistemas de pensamento, objetivos, ritmos e modos de vida. Existe, de modo geral, uma tendência das Instituições de Ensino Superior (IES) a reproduzirem modelos de formação de professores/as, com uma repetição de padrões influenciados pela racionalidade moderna, com tendência à hierarquização e divisão de conhecimentos. Portanto, é de grande importância um olhar atento e contínuo sobre as formas como se manifestam as relações interculturais nesse tipo de formação, bem como uma busca de maior compreensão do pensamento indígena, para que a relação de colaboração intercultural possa ser realmente vivenciada. Nessa direção, a obra do filósofo argentino Rodolfo Kusch apresenta relevância como uma das bases teóricas da presente reflexão, em função do seu importante e profundo estudo sobre o pensamento ameríndio, a partir da investigação com indígenas Quechua no Peru.

Kusch (2009) esclarece, por exemplo, que no pensamento indígena há um predomínio do sentir sobre o ver, pois a realidade é sentida a nível afetivo antes de ser vista. Este registro 
da realidade através do sentimento traz a forte presença da afetividade, que para o pensamento ocidental tem um tom pejorativo. A afetividade e o sentimento se mostraram muito presentes e vivos nas atividades do curso, nos materiais produzidos e nas falas dos/as participantes. Como exemplo, podemos destacar o depoimento de uma professora indígena, após a atividade de escrever e desenhar histórias de sua infância: "Gostei muito de trabalhar o lado afetivo, coisas de quando eu era criança, como as histórias que eram contadas. Nunca imaginei que iria escrever e desenhar isso".

A alegria se revelou como uma emoção fundamental, presente no cotidiano das atividades, na forma de brincadeiras, anedotas e risadas. Muitas vezes solicitavam a realização de dinâmicas e brincadeiras, para "alegrar as aulas", e se referiam às diversões que costumam fazer em suas escolas e comunidades: "Nas comunidades as crianças conhecem muitas brincadeiras e jogos. O professor pode ajudar a construir as regras do jogo".

Brincar é pedagógico. Tive muitas experiências no trabalho, como na vida. Quando fui pra cima, na escola da comunidade Juruti, numa ilha, eles tinham perdido a língua. Eu fazia brincadeiras onde todo mundo participava, até os velhos, toda a comunidade. Fazia barquinho de madeira e palha, amarrado com cipó, material todo da cultura mesmo. Fazia dia de feira, com frutas, verduras, peixe, caruru, saúva, tucupi, tudo da região, que é rica em alimento. Tinha abertura, cada responsável de barraquinha inventava uma brincadeira. Criava dinheiro falso e distribuía nas barracas. Criança, velho, adulto, tudo. Cada brincadeira e comida tinha seu valor. Era o dia todo. $\mathrm{Na}$ noite tinha apresentação da cultura, mito, história, piada. No fim viam quem era o vencedor da barraca, quem ganhava mais. Fazia brincadeira que anima, ativa as pessoas. É muito bom a gente brincar. Todo mundo participa. Ninguém fica lá sentado. (Professor indígena, 2015).

Kusch (2009) destaca também a relevância do simbólico, que possibilita o acesso a saberes referentes a uma totalidade que não pode ser alcançada com um pensamento puramente racional, explicativo, fundamentado nas causas. Os símbolos, presentes nos mitos, nos sonhos, nas metáforas, conectam com arquétipos da dimensão espiritual e emocional, trazendo significados importantes que oferecem o sentido mais profundo da cultura, o que pode ser visualizado na seguinte explicação de um professor indígena: “A base da educação tradicional são as mitologias. Cada pequena parte do mito se aplica na vida das pessoas". 
Durante a formação, diversos símbolos foram mostrados nas imagens que desenhavam, representando suas histórias e mitos. Na segunda etapa do curso foi trabalhado o tema da origem do universo sob a perspectiva de três troncos linguísticos do alto rio Negro: Tucano, Baniwa e Yanomami. No encerramento, realizado no auditório do IFAM, os grupos apresentaram seus trabalhos, trazendo objetos, mostrando desenhos, expressando através de dramatização, com músicas, figurino, narração, máscaras, roda de dança e comida típica.

Kusch (2009) ressalta ainda que a tradição indígena é ritualizada, estando relacionada com o sentimento de totalidade que se expressa nos rituais, através dos quais são afirmadas as raízes ancestrais e existenciais. Ao longo da formação, os rituais não somente foram citados e narrados pelos/as indígenas, mas também vivenciados. Na atividade do encerramento da primeira etapa, por exemplo, eles/as realizaram o ritual do Dabacuri, uma oferenda típica dos povos indígenas da região, onde foram entregues cestos com frutas, feitos com folhas de bananeira, para os/as formadores/as do curso, em meio a danças e músicas. E no encerramento da segunda etapa, representaram uma roda de ipadu (coca), com um Pagé passando um charuto feito de papel.

Outro elemento importante do texto de Kusch (2009) se refere ao predomínio do coletivo sobre o individual e do todo sobre a parte, sendo que a espiritualidade desempenha um papel importante nesta conexão. Mamani (2005) aponta para o sentimento de se unir e se reconhecer no todo, a partir do qual se origina o Ayni, que significa a reciprocidade, a correspondência mútua, a força que conecta ao conjunto e ao coletivo, formando uma convergência entre o bem estar dos outros e de si mesmo, de modo que o que ocorre no interior da pessoa também acontece no exterior. Desse sentimento surge a vontade de ajudar, de buscar o benefício dos outros, que oferece sentido ao desenvolvimento individual. É desta concepção que nasce o Ayllu, que significa a comunidade não só a nível humano, mas com tudo o que existe, de onde aparece a ideia do "nós" em um significado mais profundo, de unificação e de superação da individualidade.

Essa importância da coletividade, a qual é fortalecida pela colaboração e a reciprocidade, se manifesta na percepção indígena relativa à interculturalidade. A preferência pelo coletivo foi muito nítida, principalmente no que diz respeito aos "parentes", modo como se referem aos indígenas de qualquer etnia, como aparece nesses comentários: "Como é boa essa troca de experiências que cada parente carrega nas suas mochilas de várias regiões!". 
"Nossa voz aqui está boa, mas voltando pra comunidade, como vai ser trabalhando sozinho?”. "Interculturalidade também é entre as etnias, formar rede de saberes e de aprendizagens".

O seguinte depoimento mostra a importância da cooperação para o aprendizado indígena na educação escolar e na formação de professores/as:

No trabalho em grupo a gente vai se ajudando. Um sabe melhor o desenho, outro tem a letra melhor, outro a língua indígena, outro o português. O curso proporciona integração entre etnias e grupos, e aprendo com as ideias dos colegas. Cada um tem uma comunidade, uma realidade diferente. No curso ficamos conhecendo, trocando. Aprendo com cada um alguma coisa, reaprendo o que já tinha esquecido. Os professores brancos também aprendem com nossa cultura. A gente aprende mais como organizar o conhecimento, como trabalhar com os alunos. Importante levar isso pra comunidade. (Professor indígena, 2015).

Mas o valor do coletivo apareceu também na relação com não indígenas, como nessa fala de um professor Baniwa: "Eu gosto de parcerias com instituições e pessoas, a gente aprende muito". Dizeres como esses proporcionam um significado de interculturalidade, e inclusive de interetnicidade, que pode ser dialogado com a noção de "interaprendizagem", a qual é proposta por Gasché (2008) como uma concepção chave para a educação intercultural, pois proporciona não somente uma troca de saberes, mas a própria construção de um conhecimento mais rico e complexo. Essa aprendizagem intercultural pressupõe a abertura para rever e transformar hábitos e convicções, construindo outros modos de ser, estar, viver, pensar, aprender e ensinar, em uma visão de diversidade e reciprocidade cultural, com contribuições mútuas e crescimento conjunto.

Essa grande riqueza da complementaridade de contribuições foi muito observada ao longo da formação, principalmente nas discussões sobre a educação escolar da região, onde professores/as e indígenas de diferentes etnias e comunidades, com formadores/as não indígenas de distintas áreas de conhecimento, aprenderam mutuamente, trocando conhecimentos, contribuindo com suas experiências e ideias para o fortalecimento de estratégias educacionais de revitalização de línguas e tradições. Seguem algumas manifestações nesse sentido: "A nossa luta é a construção da educação escolar indígena, 
somos construtores, precisamos nos fortalecer juntos". "Todos temos conhecimentos, nós temos que ser fortes juntos, pois o poder vem de cima pra baixo".

O significado da coletividade também foi trazido pelos/as professores/as indígenas da formação através de dizeres que expressam a conexão com a natureza e seus elementos, como que compondo uma mesma família: “A natureza pra nós é como se fosse nosso irmão. Se tem cinco cachos de banana, vamos tirar só um. A nossa forma de vida é muito aplaudida por quem só sabe destruir". "Precisa educar o país, mostrar como os indígenas aprenderam a viver milenarmente sem destruir a natureza. Precisa construir o bem viver defendido pelos povos indígenas."

O Bem Viver, conforme Bailone (2012), se refere ao paradigma indígena constituído por uma vida de harmonia entre humanidade e natureza. Na Bolívia é utilizado o termo "Vivir Bien" e no Equador "Buen Vivir", aludindo às palavras suma qamaña em aymara e sumak kawsay em quechua. Como explica Mamani (2010, p.79), significa uma vida de relação de respeito por todos os elementos da existência, fundamentada na concepção de que tudo está conectado e que o dano a uma parte afeta seu conjunto, deteriorando a vida.

Mamani (2005) explica a cosmologia dos povos indígenas andinos como a ligação entre duas forças convergentes, a cósmica, proveniente do universo, do céu; e a telúrica, que vem da terra. A conjunção destas duas energias se expressa em todos os processos vitais, gerando e mantendo as formas de vida, que na visão de mundo ameríndia incluem os processos orgânicos e inorgânicos. As relações entre essas diversas manifestações da existência apresentam como fundamento a reciprocidade e a complementaridade. Essas características são muito presentes nas falas e no modo de viver dos povos indígenas, mostrando uma visão holística da realidade.

Esse pensamento também contribui para a interculturalidade na educação, através do estabelecimento de relações entre conhecimentos de diferentes culturas, além de colaborar para uma prática pedagógica interdisciplinar, como pode ser exemplificado nesses depoimentos registrados durante o curso: "O que estou estudando na sala de aula está relacionado com o que está no rio, na mata. É a nossa ciência”. "A aprendizagem é integrada, na roça, no rio". "Ensinamos a matemática com elementos da natureza, junto com ciências e geografia; pesquisando formas geométricas da natureza e das pinturas corporais". "Com o trabalho de pesquisa sobre a história da comunidade, envolvemos todas as disciplinas, o 
cuidado com o ambiente, como faz o beiju ${ }^{1}$, a caça, a pesca, a coleta de fibras e frutos silvestres". "Trabalhamos com plantas medicinais, benzimentos, construção de canoas, histórias sobre o mato, os animais e as plantas".

A formação apresentou a arte como um elo que conecta as diversas áreas de conhecimento, bem como as diferentes etnias e culturas, além de constituir um elemento fundamental para registros e expressões de saberes indígenas. A arte também tem um papel essencial na manifestação da espiritualidade, do sentimento e do bem viver, de forma estética, simbólica e metafórica, proporcionando expressões emocionais e transmitindo mensagens. A seguinte fala de um participante mostra a relevância da arte na função do educador: "O professor também precisa ser artista. Como ensinar práticas de sobrevivência, artes tão vivas, pinturas, caça, pesca, brincadeiras, danças, vestimentas, festas? Como comunicar”?

As crianças gostam muito quando a gente trabalha com história e desenho. Quando começa a contar a história ela já começa a desenhar. A gente sempre pergunta se já conhece a história. Primeiro apresenta o desenho e questiona o que vê no desenho: rio, pedras, pássaros, maçarico, pica-pau. Quais os personagens da história? Primeiro contamos na língua e depois no português. As mensagens das histórias sempre estão ligadas a dificuldades e potenciais da vida, como essa: pra não perder tem que estar junto. (Professor indígena, 2015).

Junto com a arte, a prática reflexiva, a pesquisa, a construção participativa e o registro coletivo constituíram componentes essenciais da estratégia educacional intercultural dessa formação. A interdisciplinaridade se apresentou como um princípio importante, constituída por movimentos de diálogo e interação entre diferentes formas de saberes, de modo a facilitar a aprendizagem e a produção de conhecimento, na superação da disciplinaridade como rígida divisão e classificação entre categorias cognitivas. A concepção sistêmica de educação foi trazida como forma de valorização dessas potencialidades de conexão entre áreas de conhecimento, de forma que contextos de aprendizagem possam ser aproveitados, relacionados com as demandas das aldeias, de um modo prático.

\footnotetext{
1 O beiju é um alimento brasileiro, de origem indígena, feito com um amido obtido da raiz da mandioca.
} 
A utilização dos conhecimentos de várias disciplinas para resolver determinada questão constitui uma abordagem que pode contribuir para ações reflexivas em conexão com a realidade das comunidades, seus problemas e projetos de futuro, proporcionando a compreensão das questões com diferentes pontos de vista. Abbonizio (2013), a partir de estudo de caso da Escola Indígena Khumuno Wu'u, do território do povo Kotiria (Wonano), localizada no alto rio Uaupés, município de São Gabriel da Cachoeira, identifica na reflexão Kotiria sobre o que querem da educação escolar, que seus planos são elaborados a partir de uma visão da escola como espaço importante de reunião comunitária, debate e intervenção na realidade local, não somente para o contexto atual, mas também para as próximas gerações. Esta visão proporciona uma educação que integra a teoria e a prática, reunindo saberes e habilidades dos estudantes em ações e objetivos coletivos.

Este tipo de ação reflexiva se manifesta no manejo do mundo, expressão que tem sido utilizada em processos de construção e consolidação das escolas diferenciadas da região. Silva \& Cabalzar (2012) relatam que em escolas no alto rio Negro, criadas por associações intercomunitárias, a preocupação com as formas próprias de conhecimento para o manejo do mundo tem gerado construções inovadoras de metodologias e de conhecimentos. Com relação à Escola Indígena Diferenciada Tuyuca, também do alto rio Negro, Johannessen (2012) a analisa como uma escola que não está separada do seu ambiente, sendo focada em valores coletivos e formas próprias de aprendizagem.

Algumas iniciativas estão experimentadas no âmbito do levantamento e do registro de conhecimentos, de forma associada à educação escolar indígena. Cabalzar (2010) destaca a importância do ensino pela pesquisa participativa em escolas indígenas diferenciadas da região, com experiências de manejo ambiental, e com o uso de metodologias diversas, incluindo discussões, diagnósticos, planos de ação, aprofundamento de saberes próprios, monitoramento e avaliação de procedimentos. De acordo com Diniz (2011), o ensino pela pesquisa foi adotado como princípio educativo e assumido pelos professores Baniwa/Coripaco como estratégia metodológica que organiza todas as atividades curriculares. Conforme essa proposta, todo o conhecimento acessado e/ou produzido pela pesquisa é sistematizado, registrado e divulgado entre as comunidades.

Esses processos educativos contribuem ainda para outro importante fator: a autonomia dos povos indígenas. Segundo Luciano (2013), a busca pela formação escolar no alto rio 
Negro também está relacionada com a demanda por um maior empoderamento sociopolítico indígena. A escola é vista como oportunidade de construção da autonomia, fortificação e formação de novas de lideranças.

Conforme revelado de diferentes formas durante o curso, esse fortalecimento das etnias e comunidades indígenas passa pela revitalização e o registro de seus conhecimentos: "Educação indígena é pra mostrar que temos nossa literatura. A literatura indígena está em cada um de nós. Nossos velhos são bibliotecas, se morrem se perde. Precisamos lembrar o que foi esquecido." "Tem que filmar, relatar, escrever, desenhar. Precisamos de CD, computador, HD externo, são nossas ferramentas." Falas como essas mostram um importante papel dos processos de formação de professores/as indígenas como apoio para a reconstrução de suas memórias, proporcionando instrumentos para a compilação, organização e registro de saberes. Essa função traz a relevância de se refletir e praticar relações interculturais que contribuam para a valorização do pensamento indígena e a descolonização da educação.

As universidades no Brasil foram implantadas em um contexto colonizador e posteriormente ligadas ao projeto de crescimento econômico do país, de modo que em geral ainda prevalece o pensamento de origem europeia, abordado como superior a outras formas de compreensão, contribuindo para a desvalorização de muitos saberes tradicionais, populares e originários. Conforme Candau (2010), a instituição escolar teve função fundamental no processo de homogeneização cultural, através da difusão de uma cultura comum eurocêntrica, tendo como consequência o silenciamento e ocultação de imensa diversidade de saberes e experiências.

Os impactos de todo esse processo colonizador são muito fortes, como mostram alguns depoimentos durante o curso: "A gente tem timidez como profissionais, falta autoconfiança". "Esta desvalorização que nós temos está prejudicando nossa forma de trabalhar". "Os pais não sabem mais o que a cultura indígena, tem alunos que nem sabem como fazer beiju". "Muitos alunos não querem mais saber da língua materna, dizem que não são mais indígenas". "A comunidade não decide o que quer: dizem que querem aprender a língua indígena, mas quando o professor trabalha falam que querem o português".

Não obstante, a América Latina, com sua diversidade étnica e cultural, apresenta grande riqueza de conhecimentos com potencialidades de contribuições para as próprias instituições educacionais e para a sociedade em geral, sendo fundamental transformar o 
enfoque epistemológico e pedagógico, através de um processo intercultural de revitalização de conhecimentos tradicionais e linguísticos.

Nesse sentido, pode ser destacada a perspectiva da interculturalidade crítica, atribuída por Walsh (2010) como um processo contínuo de negociação, construído como projeto político, ético, social e epistêmico, que afirma a necessidade de transformação nas estruturas e relações de poder que alimentam a desigualdade, discriminação e dominação. Walsh (2007,) argumenta que o conceito de interculturalidade para a América Latina apresenta um significado de resistência dos povos indígenas e negros, no sentido da construção de um projeto social, cultural e político voltado para a descolonialização do poder, do saber e do ser, o que implica em um processo de construção de outro paradigma, pensado através de uma práxis política, mas que não se limita ao político, abrangendo todo um sistema de pensamento filosófico, com outras formas de ser, pensar, agir e se relacionar. A abordagem da interculturalidade crítica também é ressaltada por Bailone (2012), ao realçar o movimento do Bem Viver como uma forma de descolonização e de inovação, constituindo uma reinvenção da democracia, que demanda revisões profundas e drásticas dos postulados culturais ancorados em visões colonialistas, desenvolvimentistas e neoliberais.

Com esse direcionamento, programas de formação de professores/as indígenas que incluem pesquisa e registro de conhecimentos e práticas relacionados com o Bem Viver, constituem estratégias de fortalecimento cultural, oferecendo importantes potenciais de contribuição para a uma trajetória mais ampla de descolonização, junto a processos contínuos de análise e reflexão crítica sobre a trajetória histórica e atual de relações interculturais de poder.

\section{Considerações finais}

A reflexão parte da relevância de uma maior compreensão do pensamento ameríndio, desenvolvendo conexões entre expressões de educadores/as indígenas e autores que contribuem para esse entendimento, mostrando a essencialidade dos elementos simbólicos, míticos, artísticos, comunitários e afetivos na sua concepção de mundo e modo de vida, sendo destacada a importância da presença desses aspectos nas relações interculturais da educação escolar e da formação de professores/as indígenas. Com essa visão, é trazido o potencial da 
contribuição do pensamento ocidental, com seus conhecimentos, métodos e tecnologias, em processos formativos interculturais de professores/as indígenas, de forma participativa e criativa.

A formação investigada, a qual constituiu a base para essa discussão, revelou uma pequena amostra da grandeza cultural do alto rio Negro, a partir do olhar de professoras e professores indígenas das etnias Yanomami, Baré, Tukano, Tariano, Dessano, Piratapuia, Kuripaco e Baniwa, do município de São Gabriel da Cachoeira / AM. Ao longo de todo o processo, a turma se dedicou na elaboração conjunta de métodos e de materiais pedagógicos, com alegria, entusiasmo e dedicação, mostrando sua grande sabedoria, seus dons artísticos e o valioso conhecimento que ainda perpetuam dos seus ancestrais.

O trabalho mostra o valor e o potencial desse tipo de formação continuada, com abordagens construtivas, práticas, artísticas e lúdicas, enfatizando o ensino através da pesquisa, gerando a produção conjunta de métodos diferenciados e materiais pedagógicos, fortalecendo a autoria indígena. Pode ser destacada a própria construção de materiais didáticos indígenas como um importante método de ensino aprendizagem, o qual poderia ser mais desenvolvido em atividades de formação de professores indígenas e nas suas atividades de docência, aprimorando a capacidade criativa de estudantes dos diversos níveis de ensino, junto a atividades de pesquisa, produção e sistematização de conhecimentos.

Foi observado, e revelado pelos participantes, o profundo significado de estar revitalizando, registrando e apresentando em diferentes linguagens, os conhecimentos de seus antepassados, produzindo formas de perpetuação e fortalecimento dessa memória através da Educação Escolar Indígena. Desse modo, pode ser observado um importante papel das formações de professores/as indígenas na colaboração para a sistematização e registro desses saberes, proporcionando recursos, estruturas, equipamentos e métodos que possam facilitar formas de compilação e de apresentação dessas importantes informações. O trabalho mostrou ainda a potencialidade de contribuição dessas estratégias formativas para processos descolonizadores, dentro de uma visão intercultural reflexiva e crítica, no sentido de minimizar ou reverter os graves impactos de todo um histórico e uma atualidade ainda colonizadora.

Produções desse tipo apresentam grande relevância, não somente para as escolas e povos indígenas, mas também para toda a sociedade, sugerindo outros modos de vida, 
fundamentados no Bem Viver, paradigma de extrema importância, considerando a crise mundial da sociedade contemporânea.

A atualidade mostra um contexto de progressiva hegemonia do pensamento neoliberal, constituindo uma civilização conduzida pela lógica do mercado e direcionada para a competição, a produção e o consumo. Esse padrão é continuamente alimentado através da mídia, com a naturalização da globalização econômica e da expansão do capitalismo como o único sistema viável, apesar da geração de crises crescentes em múltiplas dimensões, incluindo insustentabilidade econômica, desigualdade e exclusão social, discriminação e erosão cultural, degradação ambiental, corrupção e manipulação política, com violências e conflitos generalizados.

Esse panorama apresenta a demanda de profundas e abrangentes mudanças na sociedade, tendo a educação um papel importante no urgente processo de transformação. No entanto a instituição escolar foi criada em um formato direcionado para manter o status quo, sendo necessárias reflexões e ações críticas, criativas e interculturais em direção à sua reestruturação. O paradigma do Bem Viver reúne ensinamentos e exemplos de grande importância para essa reconstrução, com suas práticas e saberes milenarmente sustentados, fundamentados nos princípios da complementaridade e da reciprocidade.

\section{REFERÊNCIAS}

ABBONIZIO, A. C. O. Educação escolar indígena como inovação educacional: a escola e as inspirações de futuro das comunidades. 2013. 193f. Tese (Doutorado em Educação) Faculdade de Educação, Universidade de São Paulo, São Paulo, 2013.

BAILONE, M. El Bienvivir: una cosmovisión de los pueblos originários andino-amazónicos. In: ZAFFARONI, E, R. (Org.). La Pachamama y el humano. Buenos Aires: Colihue; Ciudad Autónoma de Buenos Aires: Ediciones Madres de Plaza de Mayo, 2012, p. 149-158.

BARRETTO FILHO, H. (Org.). Formação avançada indígena do Rio Negro: resultado do processo de consulta realizado entre 2009 e 2012. São Paulo: Instituto Arapyaú, 2012. 98 p.

CABALZAR, F. D. (ORG.). Manejo do mundo: conhecimentos e práticas dos povos indígenas do Rio Negro. 2010. São Paulo: Instituto Socioambiental; São Gabriel da Cachoeira, AM: Federação das Organizações Indígenas do Alto Rio Negro, 2010. 217 p.

CABALZAR, F. D.; OLIVEIRA, L. A. A. Novas práticas na educação escolar indígena do rio Negro. In: CABALZAR, F. D. (ORG.). Educação escolar indígena do Rio Negro: relatos de 
experiências e lições aprendidas. São Paulo: Instituto Socioambiental; São Gabriel da Cachoeira, AM: Federação das Organizações Indígenas do Alto Rio Negro, 2012, p. 26-49.

CABAlZAR, A.; RICARDO, C. A. (Orgs.). Povos Indígenas do alto e médio rio Negro: uma introdução à diversidade cultural e ambiental do noroeste da Amazônia brasileira. São Paulo: Instituto Socioambiental; São Gabriel da Cachoeira, AM: Federação das Organizações Indígenas do Rio Negro; Brasília: MEC - Ministério da Educação e do Desporto, 1998.

CANDAU, Vera Maria Ferrão; RUSSO, Kelly. Interculturalidade e educação na América Latina: uma construção plural, original e complexa. Rev. Diálogo Educ., Curitiba, v. 10, n. 29, p. 151-169, jan./abr. 2010.

DINIZ, L. L. Relações e trajetórias sociais de jovens Baniwa na escola Pamáali no Médio Rio Içana - Noroeste Amazônico. 214f. Dissertação (Mestrado em Antropologia Social) Universidade Federal do Amazonas, 2011.

FOIRN; ISA. Mapa-livro Povos indígenas do alto e médio rio Negro: uma introdução à diversidade cultural e ambiental do noroeste da Amazônia brasileira. Brasília: Ministério da Educação e do Desporto / Secretaria de Educação Fundamental, 1998. 129 p.

GASCHÉ, Jorge. La motivación política de la educación intercultural indígena y sus exigencias pedagógicas. Hasta dónde abarca la interculturalidad? In: BERTELY, María; GASCHÉ, Jorge; PODESTÁ, Rossana (Coordinadores). Educando en La diversidad cultural: Investigaciones y experiencias educativas interculturales y bilíngües. Quito-Ecuador: Ediciones Abya-Yala, 2008. p. 279-367.

JOHANNESSEN, E. M. Desafios para o futuro das escolas em aldeias indígenas. In: CABALZAR, F. D. (ORG.). Educação escolar indígena do Rio Negro: relatos de experiências e lições aprendidas. São Paulo: Instituto Socioambiental: São Gabriel da Cachoeira, AM: Federação das Organizações Indígenas do Alto Rio Negro - FOIRN, 2012, p. 84-87.

INSTITUTO SOCIOAMBIENTAL. Visões do Rio Negro: construindo uma rede socioambiental na maior bacia (cuenca) de águas pretas do mundo. São Paulo: Instituto Socioambiental, 2008. 103 p.

KUSCH, R. Obras completas. Rosário: Fundación A. Ross, 2009, v. 2, 3 e 4.

LUCIANO, G. J. S. Educação para o manejo do mundo: entre a escola ideal e a escola real no alto rio Negro. Rio de Janeiro: Contra Capa; Laced, 2013. 229 p.

MAMANI, F. H. Visión cósmica de los Andes. La Paz: Editorial Armonia, 2005. 19 p.

MAMANI, F. H. Buen Vivir/Vivir Bien - Filosofía, políticas, estrategias y experiencias regionales andinas. Lima: Coordinadora Andina de Organizaciones Indígenas - CAOI. 2010. $120 \mathrm{p}$. 
MENEZES, M. Desafios, avanços e retrocessos na educação escolar indígena. In: CABALZAR, F. D. (ORG.). Educação escolar indígena do Rio Negro: relatos de experiências e lições aprendidas. São Paulo: Instituto Socioambiental; São Gabriel da Cachoeira: Federação das Organizações Indígenas do Alto Rio Negro, 2012, p. 382-385.

RICARDO, B.; ANTONGIOVANNI, M. Visões do Rio Negro: construindo uma rede socioambiental na maior bacia (cuenca) de águas pretas do mundo. São Paulo: Instituto Socioambiental, 2008. 103p.

SANTOS, Cirlene Batista dos; FARIA, Ivani Ferreira de. Os desafios da educação escolar indígena no alto rio Negro. In: VIII FÓRUM INTERNACIONAL DE PEDAGOGIA - FIPED, V. 1, 2016, Imperatriz/MA. Anais do VIII Fórum Internacional de Pedagogia - FIPED, Imperatriz: Realize, 2016.

SILVA, A. L.; CABALZAR, A. In: CABALZAR, F. D. (ORG.). Educação escolar indígena do Rio Negro: relatos de experiências e lições aprendidas. São Paulo: Instituto Socioambiental; São Gabriel da Cachoeira: Federação das Organizações Indígenas do Alto Rio Negro, 2012, p. 400-407.

WALSH, C. Interculturalidad y colonialidad del poder. Un pensamiento y posicionamiento "otro" desde la diferencia colonial. In: CASTRO-GOMEZ, S.; GROSFOGUEL, R. (ORGs.). El giro decolonial: reflexiones para uma diversidad epistêmica más allá del capitalismo global. Bogotá: Siglo del Hombre, Universidad Central, Instituto de Estudios Sociales Contemporaneos, Pontificia Universidad Javeriana, Instituto Pensar, 2007, p: 47-62.

WALSH, C. Interculturalidad crítica y educación intercultural. In: VIAÑA, J.; TAPIA, L.; WALSH, C. (Org.). Construyendo interculturalidad crítica. La Paz - Bolivia: Instituto Internacional de Integración del Convenio Andrés Bello, 2010, p. 75-96.

\footnotetext{
${ }^{\text {i }}$ Doutoranda em Educação do Programa de Pós-Graduação em Educação da Universidade de Santa Cruz do Sul, com o apoio PROSUC/CAPES. beatriz.osoriostumpf@yahoo.com.br

ii A ação Saberes Indígenas na Escola é uma Política Pública Nacional de formação continuada de professores/as indígenas, a qual ocorre em regime de colaboração com os Estados, o Distrito Federal, Municípios e Institutos de Ensino Superior (IES). Foi instituída pela Resolução nº 54, de 12 de dezembro de 2013.

iii O Programa Nacional dos Territórios Etnoeducacionais Indígenas (TEE) foi instituído pelo Decreto 6.861, de 2009, visando apoiar a implementação, avaliação e fortalecimento da Política de Educação Escolar Indígena, considerando a territorialidade das etnias, participação indígena e integração entre os órgãos públicos. O TEE foi pensado como um espaço de articulação das políticas públicas voltadas à Educação Escolar Indígena, envolvendo seus diferentes atores $\mathrm{e}$ agentes na discussão e planejamento conjunto das ações. http://www.funai.gov.br/index.php/educacao-escolar-indigena?start=7.

iv As classes multisseriadas são uma forma de organização de ensino na qual o professor trabalha simultaneamente, na mesma sala de aula, com várias séries do Ensino Fundamental. O artigo 23 da Lei de Diretrizes e Bases da Educação (LDB), de 1996, oferece uma alternativa à organização realizada por séries, com uma diversidade de possibilidades para a organização escolar, permitindo o uso de séries anuais, períodos semestrais, ciclos, alternância regular de períodos de estudo, grupos não-seriados ou por parâmetro de idade, competência ou outros critérios. Com a organização na forma de ciclos, as turmas que atendem a alunos com idades e níveis de conhecimento diferentes passam a ser chamadas de multicicladas. A realidade das escolas indígenas do alto rio Negro contempla forte presença de classes multicicladas, muitas vezes também reunindo várias etnias em uma mesma sala de aula. A disciplina "Educação Multiciclada" proporcionou a construção de estratégias interdisciplinares para facilitar a aprendizagem nesse tipo de turma.
} 